\title{
Issues of Transfer of Training from the Training Houses to the Line Department: A Case of Government Sector Department in Pakistan
}

\author{
Farooq-E-Azam Cheema \\ Department of Business Administration \\ Bahria University \\ Karachi, Pakistan \\ Nadeem A. Syed \\ Faculty of Business Administration \\ SZABIST \\ Karachi, Pakistan
}

\begin{abstract}
Purpose:Purpose of this case study and its analysis is to highlight the issue of transfer inherent with the classroom training especially in the government sector departments. Of-the-job training is an expensive investment disparate with its returns. The issue is growingly attracting the attention of the HRD writers and the practitioners.

Methodology/Sampling:The study is based on comprehensive literature reviewed critically and the diverse factors affecting transfer of training from the training houses to the line departments. The good practices from the literature were juxtaposed with the actual practices of the Directorate of Human Resource Development Pakistan Customs and Sales Tax and the line departments that directorate was serving.

Findings:In theory and practice both, measures relating to transfer of training from the training houses to the line departments is aimed at improving the organizations' individual employee's productivity and organizational performance in the result. It focuses on diverse elements and subsystems of the organization involved in the transfer of training including the training house management, the trainees, line managers and the top management of the client organizations. Involvement of the people in the process of organizational development is hall mark of this process.

Practical Implications:Findings of the case study have professional implications for the HRD practitioners, line managers and the organization management as a whole. The study entails special efforts required on part of the trainees, trainers and those in-charge in the organizations to
\end{abstract}

Keywords: Trainers, trainees, line managers, transfer of training, bureaucratic system.

JEL Classification: O200.

\footnotetext{
* The material presented by the authors does not necessarily portray the viewpoint of the editors and the management of the Institute of Business \& Technology (IBT).

* Farooq-E-Azam Cheema: dr.cheema@live.com

* Nadeem A. Syed: drnadeemsyed@ gmail.com

CJMSS is published by the Institute of Business and Technology (IBT). Main Ibrahim Hydri Road, Korangi Creek, Karachi-75190, Pakistan.
} 


\section{INTRODUCTION}

Transfer of training has been defined as the generalization of the skills acquired during the training phase to the work environment and the maintenance of these acquired skills over time (Baldwin et. al., 1988). The success or failure of the training programs is determined by the degree of success or failure which is displayed by the trained individuals in their jobs (Analoui, 1993). So, for the individuals as well as the organizations, this is the point where the real payoff from training lies (Robinson et. al, 1989) and if there is no transfer of training to the job everyone, the organization, the trainer, and the employee, loses (Robinson, 1985).

The topicality of the transfer of training issue emanates from the broadly recognized difficulty in achieving it positively (Tuomi-Grohn et. al, 2003). Unlike the case of the learning-through-doing, the concern for transfer of what is taught in the classrooms to the job is inherited with the off-the-job leaning programs (Guile et. al, 2003) owing to their physical separation from the workplace (Donovan et. al., 2001). And this concern is fast deepening worldwide owing to growing disparity between the effectiveness of these training programs and the cost incurred on them (Pfeffer et al, 1999; Eddie et. al., 2001). Though off-the-job training itself is an expensive investment (Eddie et. al, 2001), not more than $10 \%$ of its expenditures actually result in positive transfer to the job (Geargenson 1982). So the issue is growingly attracting the attention of the HRD writers and the practitioners (Wexley et al, 1986).

In this work we will be discussing this critical matter of transfer of training from the training houses to the line departments with reference to the case of Directorate of Human Resource Development Pakistan Customs and Sales Tax.

\section{FACTORS EFFECTING TRANSFER OF TRAINING}

Transfer is a complex process which encompasses individual abilities and motivational factors within the work environment, learning processes and situations, individual expectations and their unique frames of references, and the organizational environment in general (Analoui, 1993). It means that the following three actors, influencing and being influenced by each other and the environment, determine the degree of effectiveness of the transfer of off-the-job training to the job:

1. Trainee - the level of motivation and ability to learn and to apply it on the job (Mosel, 1957; Elangovan et. a 1,1999; Donovan et. al 2001; Broad et. al. 1992; 1999; Noe, 2000)

2. Trainer - creating the learning environment (Analuoi, 1993) and keeping the course contents relevant to the job (Broad et. al. 1992)

3. Managers/ Organization - nature of the work environment where the newly acquired knowledge and expertise is to be used and support provided in that regard (Baumgartel et. al, 1984; Analoui, 1993; Broad et. al 1992; Hayes et. al, 1989).

To make the transfer of training successful a clearly defined system is needed which unites the trainer, trainee, and the manager together, where possible (Leifer et. al, 1980). 
This, in turn, is possible only when the HRD activities are linked to the organization's strategic direction wherein the trainers are part of the strategic planning process and give expert advice on workforce development implications (Chalofsky et. al, 1988).

Furthermore, there is widespread but erroneous perception that transfer of training needs attention only after training has been completed (Broad et. al 1992). Whereas the research proves that there are number of barriers before and during the training as well, and the trainees, trainers and the managers have to play role in all three phases (ibid).

\section{ROLE OF THE TRAINEES IN TRANSFER OF TRAINING}

The trainees' role in transfer of training is implied in the degree of their self-management (Noe, 2000) and self-efficacy (Elangovan, 1999). The term self-efficacy refers to belief in one's capabilities to mobilize the motivation, cognitive resources, and courses of action needed to meet the given situational demands (Wood et. al. 1989). The writers like (Gist, 1989; Steven et. al, 1996; Machin et. al., 1997) believe that there is a strong correlation between the self-efficacy or the learner confidence (Warr et. al, 1999) and the intention to transfer knowledge and skills from off-the-job training program to the job. The degree of self-management and self-efficacy of the trainees have cause and effect relationship with the following:

1. Trainees' motivation level to learn and apply it on the job

2. Trainees' ability to learn

\subsection{Trainees' motivation level}

Same as 'a horse can be taken to the water but cannot be forced to drink it' (Kenney et. al., 1986), only having positive reasons to learn something can make the trainees learn successfully. There is consensus among the writers like (Simpson 1980, Smith 1982, Brookfield 1986, Knowles 1990) that adults are motivated to devote energy to learning most effectively only when they perceive that it will help them perform tasks or deal with problems that they confront in the life situations.

So, 'what is in for me?' is the question of the participants that the parent organizations and the training/education institutions have to solidly answer if they want to make the training program make of any value and get the learning transferred to the job (Broad et. al., 1992). The organizations can answer this question through establishing a connection between learning and the career development (ibid). More this connectivity is clear in terms of the policy and practice brighter is the chance of transfer of learning to the workplace (ibid).

Consequently, what is observed is that the trainees who have both career planning and a high level of job involvement are more motivated to learn (Williams et. al, 1991) since they recognize the importance of learning new skills (Facteau et. al, 1995) needed to enhance their employability (Torrington et. al, 2002). This motivation level is reflected in the training phase in the form of regular attendance and concentration on the contents (Analoui, 1993), and in the post-training phase in the form of making extra efforts to apply those contents on the job (Broad et. al., 1992). 


\subsection{Trainees' ability to learn}

The contents not learned can never be transferred (Broad et. al, 1992) nor will they create any element of self-confidence among the participants. So the necessary requirement for securing the objective of transfer of learning to the job is to make sure that an effective level of learning of the training has taken place (Mosel, 1957; Analoui, 1993; Elangovan, 1999). Butall the participants are not same on the scale of the ability of 'learning to learn' (Harrison, 2005) which is the central training problem of the day (ibid). Main constituents of the ability of 'learning to learn' are the participants' cognitive ability (Noe, 2000), academic ability (Harrison 2005), threshold of the existing knowledge (Delahaye, 2000), and their learning style (Honey et. al., 1989) etc. - collectively called the 'baggage' (Marchington et. al 1996) that the participants bring with them to the classroom.

Since every participant brings different baggage to a particular learning program, the ability to learn may vary from person to person. For instance, those participants who are activist (Honey et. al., 1989) by learning style may feel less comfortable in learning through the classroom learning program as compared to those who have preferably theorising (ibid) or reflecting (ibid) as their learning styles. However those participants remain in advantage and can take optimum benefit of any learning opportunity who learn through every learning mode and can adapt their own learning style to the particular situation (Kolb et. al., 1984).

But role of the trainees in case of the Pakistan Customs and sales Tax is not encouraging one in connection with learning and transferring it to the job since the bureaucratic system itself has little to offer them to earn for their careers from the developmental programs. Being synonymous with seniority based promotions alone, career in this department is stable and well predictable, and everyone knows her/his destination with respect to certain time. Internal growth has no more bearing over the external career (Herriot, 1992; Schein, 1993; Yahuda, 2004). Career is lifetime (Weber, 1904) that reaches the plateau only on day of superannuation. Complacence is abundant since once appointed no one can be easily expelled from the service. So developing intrinsically and achieving professionalism through developmental mechanisms is extraneous to the concept of career in this organization.

\section{ROLE OF THE TRAINERS IN TRANSFER OF TRAINING}

The trainers have an indirect role to play in transfer of training through imparting maximum learning among the trainees (Broad et. al., 1992) by the ways of creating conducive learning conditions (Shiver, 1980), employing the appropriate training methods (Analoui, 1993), doing optimum effort to employ the theory of identical elements (Thorndike, 1901 cited in Noe, 2000), and designing the training contents relevant to the job (Elangovan et. al., 1999).

The apprehension of irrelevance of the training contents in case of the off-the-job training programs is not extraneous owing to their traditional trainer-cantered orientation (Knowles, 1990) wherein the trainer in an 'omniscient' role and expert purveyor of the knowledge (Stafylarakis et. al 2005), diagnoses the learning needs, sets the learning goals, selects the medium of instruction, and decides the evidence of accomplishment of learning 
(Knowles, 19990) irrespective of the learning needs and learning style (Honey et. al, 1989) of the participants.

In such situation, being continuously on the receiving ends (Brookfield 1986), the participants may lose the ownership of learning (Torrington et. al 2002) especially when they feel that the training contents are not relevant to the job which has a dampening effect over their motivation to learn the contents offered and then to apply them on the job.

To what extent the 'best practices' taught in these training programs are relevant to the participants' work context depends upon the degree of similarity between the countries and the organizations (McCourt et. al, 2003). The convergence view (Negandhi et. al 1979) sees the organizations in the different countries essentially similar, or at least that they are getting more and more alike - under the concept of globalization. Whereas the divergence argument (McCourt et. al, 2003), on the other hand, is that the differences between the countries and between the organizations are profound, and are more likely to increase than to disappear.

Thus, if the state of convergence is dominating in a given situation, the reality gap between 'what should be done' and 'what actually is going on' (McCourt et. al, 2003) will be minimum and the participants will be more valuing the training/education offered (Baumgartel et. al, 1984) and will be more motivated to learn with the intention to adopt it on the job (McCourt et. al, 2003). But the situation will be different if the reality gap between the 'what should be' and the 'what actually is' is higher owing to dominating state of divergence. In such situation, the participants, taking the contents irrelevant, are likely to devote less time and effort to learn the training contents (Elangovan et. al, 1999).

No doubt, we (The Directorate of Human Resource Development) also rely on the 'good practice' models for designing the training curricula especially relating to the soft management skills but we try to seek the state of crossvergence (Ralston et. al, 1997) through a conceptual interaction between the 'best practice models' and the real context of the line departments and to exhort the trainees to adapt the former according to the needs of the latter and synthesize the 'appropriate practice' (McCourt et. al, 2003) out of this interaction.

\section{ROLE OF THE MANAGERS / EMPLOYER ORGANIZATION IN THE TRANSFER}

The most significant barrier to transfer is lack of support to the returnees in applying training to their job (Broad et al, 1992). That is why the transfer of training needs to be taken as a socio-technical phenomenon which ought to be understood and dealt with the context of the work relationship (Analoui, 1993). The immediate boss, his attitude and managerial style towards work and people remain the most important factors which affect the process of converting the learnt skills and knowledge into practice (Broad et. al, 1992; Tannenbaum et al, 1992). Support provided by him acts as a cushion for the employees for their softer landing in the world of work and face the social reality of the workplace after having acquired knowledge and skill in the different environment (Analoui, 1993).

Oppositely, the relational factors that prohibit application of the learning to the job include the low receptivity of the bosses and the colleagues to new ideas (Newstrom, 1986; Tannenbaum et. al, 1992), their strong commitment to rules and procedures which inhibit innovation and improvement (Hayes et. al, 1989), the group norms which discourage the transfer of learned skills (Elangovan et. al, 1999), and the time and work pressures 
(Broad et. al 1992); all the factors which make the returnee to relapse to olden work habits.

The managers are needed to act in the pre-training phase as well to substantially create pre-training motivation (Eddie et. al., 2001; Facteau et. al., 1995) among the participants which is base of the learning in a training program (Mathieu et. al., 1992; Noe, 2000) and its subsequent effective transfer to the job (Huczynski et. al, 1980). So they should take the steps like taking input from the trainees regarding training decision (Eddie et. al., 2001), encouraging them to participate the training/education program (Baldwin, 1988), communicating to them the scope and usefulness of the program for their career (Harrison 2005), and empowering them through holding them accountable for the learning and applying it to the job (Mosel 1957).

The organizational culture in general also has a pivotal role to play in the matter of transfer of training (Baumgartel et. al, 1984). An organizational culture that fosters employee development and growth and encourages employee initiative leaves a positive impact over the transfer of training (Elangovan et. al, 1999). But the bureaucratic environment like that of the Pakistan Customs and Sales Tax which, ipso facto, encourages the precedents and past practices to follow and dampens creativity, innovation and risk-seeking behaviour of the individuals on the job (Blau 1971), is not a fertile ground for application of the new ideas, hence an impediment by itself to the transfer of training.

\section{CONCLUSION}

Transfer of training is not an easy task (Broad et. al, 1992) nor the traditional belief held by the trainers that the transition of learnt knowledge and skills follows automatically on the job, carries any sense or basis (Analoui, 1993). Rather, special efforts are required to be made by the trainees, trainers and those in-charge in the organizations to facilitate and accelerate the process of transfer through a strong relationship among the managers, trainers and the trainees (Broad et al, 1992; Analoui, 1993). Broad et al, 1992 call this collaborative relationship the 'transfer of training partnership' (TTP). The theme of this partnership is that the organizations cannot typically rely merely on the voluntary or unsupported transfer that involves higher input but yields abysmal output. Rather, additional level of effort is needed for 'stimulated' transfer through proper transfer management activities by the ways of formal coordination among the managers, trainers and the trainees. The proportion of output of training to input in cases of 'voluntary' and 'stimulated' transfer is given in the following diagram.

Figure 1

Proportion of Training Input and Output 


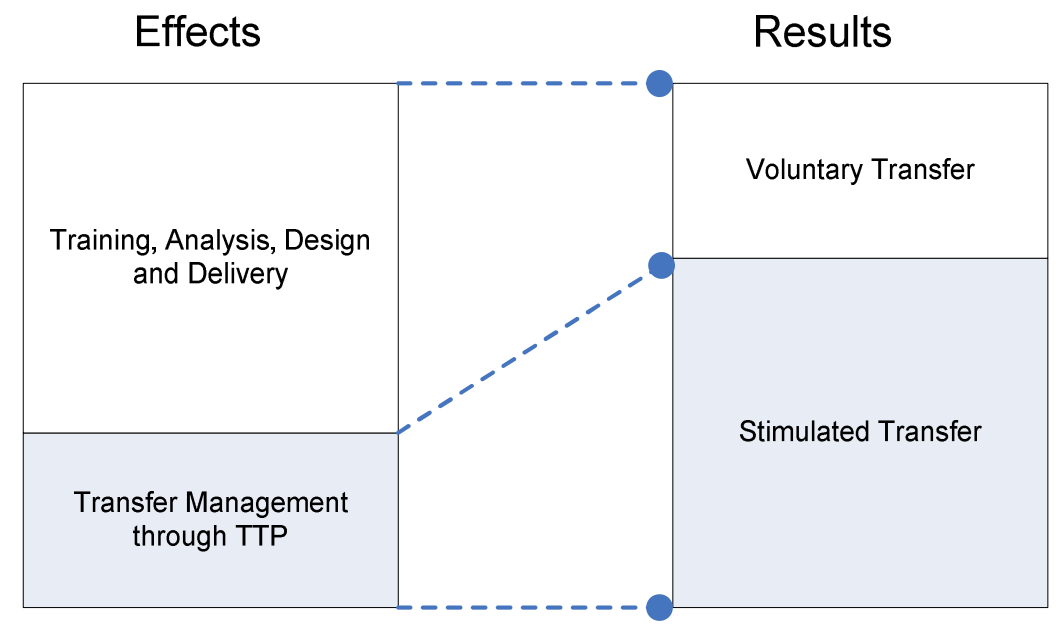

Source: Broad et al, 1992

But in the case of Pakistan Customs and Sales Tax, this partnership is near to impossible at least in the present situation wherein the training and development is nowhere in the strategic policy attics. There is hardly any functional relationship between the line departments and the Directorate of Human Resource Development. Rather, the Directorate is conducting the training programs just to meet its raison d'etre and consume the allocated budget. The line departments depute the staff for training just as an official response, and the trainees join the training programs as a matter of duty - without any objective of training near to any of these quarters. In such impersonal (Blau, 1971) bureaucratic environment wherein the vital elements of 'ownership' and 'accountability' of training and development are altogether missing, thinking about such TTP and transfer of the training to the job is not more than just a moonshine.

\section{REFERENCES}

Analoui, F. (1993) Training and Transfer of Learning, Ashgate Publishing Ltd.

Baldwin, T. \& Ford, J. (1988), "Transfer of training: a review and directions for future research", Personnel Psychology, Vol. 41

Baumgartel, H., Reynolds, M. \&Pathan, R. (1984) 'How personality and organizationalclimate variables moderate the effectiveness of management development programs: a review and some recent research findings' Management and Labor Studies, Vol. 9

Blau, P. (1971), Bureaucracy in Modern Society, Harry \& CO.

Broad, M. \&Newstrom, J. (1992) Transfer of Training, Addison-Wesley

Brookfield, S. D. (1986) Understanding and Facilitating Adult Learning, Open University Press

Chalofsky, N. \& Carlene, R. (1988) Effective Human Resource Development: How to build a Strong and Responsible HRD Function, Jossey-Bass

Delahaye, B. (2000) Human Resource Development John Wiley \& Sons

Donovan, P. , Hannigan, K. \& Crowe, D.(2001)'The learning transfer system approach to estimating the benefits of training: empirical evidence'Journal of European Industrial 


\section{Training Volume 25}

Eddie, W., Cheng and Danny C. K. Ho (2001) 'A review of transfer of training studies in the past decade', Personnel Review, 30(1)

Elangovan, A., \&Karakowsky, L. (1999), 'The role of trainee and environmental factors in transfer of training: an exploratory framework', Leadership \& Organization Development Journal, 20(5)

Facteau, J., Dobbins, G., Russell, J., Ladd, R., Kudisch, J. (1995), "The influence of general perceptions of the training environment on pretraining motivation and perceived training transfer", Journal of Management, Vol. 21 (1).

Georgensen, D. (1982) 'The problem of transfer calls for partnership', Training and Development Journal, 36 (1)

Gist, M. (1989), 'The influence of training method on self-efficacy and idea generation among managers', Personnel Psychology 42

Guile, D. \& Young, M. (2003) 'Transfer and Transition in Vocational Education: Some Theoratical Considerations' in the Tuomi-Grohm, T. \&Engestrom, Y (ed) Between School and Work: New Perspectives on Transfer and Boundary Crossing, Elsevier Science Ltd.

Harrison, R. (2005), Learning and Development, Institute of Personnel and Development.

Hayes, J. \&Pulparampil, J.(1989)Trainers' Perceptions of the Factors which Influence the Transfer of Learning: An Indian Case Study, International Journal of Public Sector Management Vol. 2 (1)

Herriot, P. (1992) The Career Management Challenges: Balancing Individual and Organizational Needs, SAGE Publication Ltd.

Honey, P. \& Mumford, A. (1989) A Manual of Learning Opportunities, Peter Honey

Huczynski, A., Lewis, J.W. (1980), "An empirical study into the learning transfer process in management training", Journal of Management Studies, Vol. 172

Kenney, J. \& Reid, M. (1986), Training Intervention, Institute of Personnel Management

Kolb, D., Rubin, L. \& McIntyre, J. (1984) Organization Psychology, Englewood Cliff

Knowles, M. (1990), The Adult learner: a neglected species, Gulf Publishing Company

Leifer, M. \&Newstrom, J. (1980), 'Solving the Transfer of Training Problems' Training and Development Journal (August) 42-46

Machin, M. \& Fogarty, G. (1997), 'The effects of self-efficacy, motivation to transfer, and situational constraints on transfer intentions and transfer of training, Performance Improvement Quarterly 10

Marchington, M. \& Wilkinson, A. (1996), Core Personnel and Development, IPD

Mathieu, J., Tannenbaum, S. \& Salas, E (1992), "Influences of individual and situational characteristics on measures of training effectiveness", Academy of Management Journal, Vol. 35 (4)

McCourt, W. \& Eldridge, D. (2003) Global Human Resource Management: Managing People in Developing and Transitional Countries, Edward Elgar Publishing Ltd.

Mosel, J. (1957) 'Why Training Programs Fail to Carry Over' Personnel Journal

Negandhi, A. \& Prasad, S. (1979), 'Convergence in organizational practices: an empirical study of industrial enterprises in developing countries', Organizations alike and unlike, Routledge and Kegan Paul 
Newstrom, J. (1986), "Leveraging management development through the management of transfer", Journal of Management Development, Vol. 55.

Noe, R. (2000), Employee Training \& Development (Int. Ed.), McGraw-Hill

Pfefer, J. \&Sutten, R. (1999) The Knowing-Doing Gap: How Smart Companies Turn Knowledge into Action, Harvard Business School Press

Ralston, D., Holt, R. \& Kai-Cheng, Y. (1997), 'The impact of national culture and economic ideology on managerial work values: A study of the United States, Russia, Japan and China', Journal of International Business Studies, 28(1)

Robinson, K. (1985), A Handbook of Training Management, Kogan Page

Robinson, D. \& Robinson, J. (1989) Training for Impact, Jossey-Bass

Schein, E. (1993) Career Anchors, Pfeifer and Co.

Shiver, C. (1980), 'What Does Training Got to Offer?' in Edmund, M. et. al. (eds) Management of Human Resources, Prentice Hall

Simpson, E. (1980) 'Adult Learning Theory: A State of the Art', Adult Development and Approaches to Learning, National Institute of Education

Smith, R. (1982) Learning How to Learn: Applied Learning Theory for Adults, Cambridge Books

Stafylarakis, M. \& Eldridge, D. (2005) 'HRD Definitions and Significance' unit 1 Human Resource Development IDPM

Steven, C. \& Gist, M. (1996), 'Effects of self-efficacy and goal-orientation training on interpersonal skill maintenance: What are the mechanisms?' Training for a rapidly changing workplace: Applications of psychological research, American Psychological Association

Tannebaum, S. \& Yuki, G. (1992) 'Training and Development in Work Orgaizations' Annual Review of Psychology, Vol. 43

Torrington, D., Hall, L. and Taylor, S. (2002) Human Resource Management, Pearson Education Ltd.

Tuomi-Grohn, T., Engestrom, Y. \& Young, M. (2003) 'From Transfer to Boundary-crossing Between School and Work as a Tool for Developing Vocational Education: An Introduction' in the Tuomi-Grohm, T. \&Engestrom, Y (ed) Between School and Work: New Perspectives on Transfer and Boundary Crossing, Elsevier Science Ltd.

Warr, P., Allan, C. \&Birdi, K. (1999), ' Predicting three levels of training outcome', Journal of Occupational and Organizational Psychology, 72

Weber M (1904), 'Bureaucracy', Essays in Sociology, reprinted in 1977 Lowe \&Brydone Printers

Wexley, N.; Baldwin, T. (1986) 'Post training strategies for facilitating positive transfer: an empirical exploration' Academy of Management journal, 29 (3)

Williams, T., Thayer, P. \& Pond, S. (1991), "Test of a model of motivational influences on reactions to training and learning", St Louis, MO .

Wood, R. \& Bandura, A. (1989), 'Social-cognitive theory of organizational management, Academy of Management Review, 14

Yahuda, B. (2004) Managing Careers: Theory and Practice, Pearson Education Ltd. 